\title{
Diet patterns of Eurasian lynx Lynx lynx: what causes sexually determined prey size segregation?
}

\author{
Peter SUNDE and Tor KVAM*
}

Sunde P. and Kvam T. 1997. Diet patterns of Eurasian lynx Lynx lynx: what causes sexually determined prey size segregation? Acta Theriologica 42: 189-201.

The influence of sex, body weight, physical condition, age and season on diet choice was investigated by hunting reports and intestinal analyses of 441 lynx Lynx lynx (Linnaeus, 1758) from Norway killed during 1960-1996. Of self-provisioning ( $\geq 1 \mathrm{yr}$ ) lynx $(n=280$ ), males preyed proportionately more upon cervids (primarily roe deer Capreolus capreolus and semi-domestic reindeer Rangifer tarandus) compared to small game (mountain hare Lepus timidus and tetraonids) than females did. Only $5.4 \%$ of the variation in prey preference towards small game and cervids $(p=0.0002)$ could be explained by sex. In a logistic regression model, no additive effect of weight or any other parameters was found after sex had been included. We did not find sufficient evidence for body weight (sensu stricto) being related to prey choice, but propose that sexually determined prey segregation in lynx is caused by different ranging behaviour resulting in different encounter rates with different kinds of prey.

Key words: Lynx lynx, sex, body weight, diet choice

Department of Population Biology, University of Copenhagen. Universitetsparken 15, DK - 2100 Copenhagen $\emptyset$, Denmark (PS); Norwegian Institute for Nature Research, Tungasletta 2, N - 7005 Trondheim, Norway (TK)

\section{Introduction}

Hunting success and food choice may be two of the most basic factors determining the fitness of carnivores. Large or medium-sized mammalian predators have few or no natural enemies. Hunting efficiency may therefore be an important, perhaps even the most important, fitness component. The long weaning times of offspring (Eisenberg 1982, Bekoff and Daniels 1984) probably also illustrate the importance of hunting efficiency for the highly carnivorous felids. Studies on food habits of mammalian carnivores have revealed that individuals of the same species, but with differences in sex and reproduction status, may prefer prey of different sizes (eg Fritts and Selander 1978, Erlinge 1979, 1981, Moors 1980, Litvaitis et al. 1984, 1986, Birks and Dunstone 1985, Matlack and Evans 1992, Heggberget and Moseid 1994, Pulliainen et al. 1995). The size of predators, a factor which in solitary carnivores is related to sex (males are on average larger than

\footnotetext{
${ }^{*}$ Correspondence address: NINA, Tungasletta 2, N - 7005 Trondheim, Norway;

e-mail: tor.kvam@nina.nina.no
} 
females), may be an alternative determining factor influencing the preferred size of prey. The sexual size dimorphism found in solitary carnivores has even been explained as an evolutionary strategy to reduce intraspecific food competition (Dayan et al. 1989, 1990, Dayan and Simberloff 1994). Hunting experience measured by age may be a third key factor affecting prey choice, since the highest recorded mortality among vertebrates is usually found among juveniles, lynx being no exception to that rule (Kvam 1990, Breitenmoser and Haller 1993).

Studies of gastrointestinal (GI) tracts are important for detecting trends in the feeding ecology of carnivores. They make it possible to distinguish variations in foraging behaviour against variables like sex, body size, general condition and age through a large number of independent observations. However, despite considerable data on the feeding habits of carnivores, studies of sex-specific diets are scarce, probably because of difficulties in obtaining appropriate data. As regards solitary mammalian carnivores, studies on diet related to sex and size have mainly been done on species of the Mustelidae (Erlinge 1979, 1981, Moors 1980, Birks and Dunstone 1985, Heggberget and Moseid 1994). In the Felidae, such studies in solitary species are, as far as we know, restricted to members of the Lynx genus. Studies of prey selection in the Felidae in relation to sex, weight, general condition, season or age and based on GI-analyses, have been carried out on bobcat Lynx rufus (Fritts and Sealander 1978, Litvaitis et al. 1984, 1986, Maehr and Brady 1986, Matlack and Evans 1992) and European lynx Lynx lynx (Linnaeus, 1758) (Birkeland and Myrberget 1980, Pulliainen 1981, Pulliainen et al. 1995). Previous studies have, however, suffered from a weakness: as differences in prey choice have been tested univariately, the effects of complicating factors such as sex and body weight, body weight and general condition, or age and body weight, have not been identified. As a consequence, the question of which factor, sex or body size, is the principal determinant of diet choice, remains largely unanswered.

The purpose of this paper is to investigate whether prey preference of the European lynx is affected by (1) sex, (2) weight, (3) general condition, (4) age or (5) season. The lynx in Norway may serve as a good model for such an analysis of the factors influencing choice of prey, because of the marked sexual size dimorphism and a high average prey weight to predator weight ratio for the most preferred types of prey. There is, moreover, a significant size difference between adult and subadult individuals. We will perform the analysis by feeding all the factors into one multivariate statistical model.

\section{Material and methods}

From 1960 to 1980 , carcasses of bounty-hunted lynx were sent to the Division for Game Research at the Directorate for Nature Management. From 1988 to 1993, the bounty was replaced by a payment for carcasses donated for scientific use. From 1994 to 1996, all lynx shot or found dead anywhere in the country had to be sent to the Norwegian Institute of Nature Research (NINA). More than $90 \%$ of lynx received had been shot, the remaining causes of mortality being car accidents, (illegal) trapping 
and poisoning (permitted in the 1960s). Because of the timing of the hunting season, the available material was mainly from the late winter.

A total of 1183 lynx carcasses were received from 1960 to 1996. For statistical reasons we selected only one prey item from each specimen for the analysis. Stomach samples were taken during $1960-1966(n=157)$ and 1988-1996 $(n=196)$. Specimens from 1967-1987 were registered, but no stomach samples were collected. The data from the first period were described by Birkeland and Myrberget (1980). We have also investigated the intestines of 9 specimens with empty or missing stomachs, from the period 1990-1995. We started from the lower intestine and took a sample of the first bolus recorded containing identifiable prey remains. The prey items in the GI-tracts were identified by macroscopic remains like teeth and claws, and by microscopic remnants of hair. Reference collections of hairs from native Norwegian mammals and skins from Norwegian galliform birds were used for comparison.

For carcasses received between 1960 and 1975, the hunters were questioned about the details of the hunting session. During the period 1966-1975, when stomachs were not investigated, 79 written reports were obtained from hunters who had identified remains of prey found while tracking the lynx prior to shooting it. The reports could be compared with stomach contents in another 46 cases from the period 1960-1966, $43(93 \%)$ of which related to the same animals. This was considered sufficient for us to include the reports in the data set. If the remains of more than one prey were found during tracking, the last prey killed was selected for the analysis.

The weight of skinned carcasses and skinned carcasses with severed legs were standardised to unskinned weight by linear regressions through the origin. Skinned carcasses: $b=1.226[95 \%$ conf. intv. $(1.200<\beta<1.251)], r_{\mathrm{P}}=0.987, \mathrm{df}=222$. Skinned carcasses with severed legs: $\mathrm{b}=1.780[95 \%$ conf. intv. $(1.727<\beta<1.833)], r_{\mathrm{P}}=0.992 \mathrm{df}=76$. For the weight dimorphism index (DI) we have used the ratio of the standardised male and female weight (after Moors 1980), but subtracted from 1.

The general physical condition of each lynx, based on the amount of subcutaneous fat on the skinned carcass, was coded by an index ranging from 1 (starved) to 5 (very fat). Animals severely weakened by starvation (fat code 1) were excluded from the analyses. Age determination was performed by counting incremental lines in the tooth cementum of the canines (Grue and Jensen 1979, Kvam 1984). We have adopted the seasonal division employed by Birkeland and Myrberget (1980), with winter from November through April, and summer from May through October, determined by the average periods of snow cover in Norway.

The lynx were divided into three separate age groups: "juveniles" ( $<12$ months old), "subadults" (12-24 months old) and "adults" (> 24 months old). The age in months was counted from 1 June of the year the animal was born. When analysing prey preference, we have only considered subadults and adults, which are known to forage on their own. Female lynx normally give birth for the first time at the age of 2 years (Kvam 1991).

The lynx is an almost obligate predatory species that normally does not forage by scavenging (Haglund 1966, P. Sunde et al. in prep). In general, items found in the GI-tracts of self-provisioning lynx can thus be considered as remains of killed prey. Since the diet of lynx in Norway is composed of a very limited number of species (Table 2), the food items were grouped into two categories: "cervids" and "small game" (mountain hare Lepus timidus and tetraonids). Rodents are considered as unimportant for the nutrition, and carnivores might be killed for other reasons than foraging, for instance due to interspecific carnivore interactions (Palomares et al. 1996). The "cervid" group is mainly composed of roe deer Capreolus capreolus and semi-domestic reindeer Rangifer tarandus. These two species differ in their regional distribution, the roe deer occurring mainly in the southern half of the country, and semi-domestic reindeer husbandry being widespread in the northern half. The distribution between the sexes of roe deer vs reindeer in the diet was tested for central Norway (defined as the counties of Sør-Trøndelag and Nord-Trøndelag), where both cervid species are widely distributed.

Lynx populations from different parts of Europe are reported to feed on different categories of prey, ranging from almost $100 \%$ hares and other small game to more than $80 \%$ ungulates 
(Jędrzejewski et al. 1993). Lynx are thus able to survive on small game as well as on ungulates as their primary source of prey. The small game species that is by far the most important, the mountain hare (2.5-5.8 $\mathrm{kg}$ - van den Brink 1955), and the smallest ungulate species, the roe deer $(\approx 20 \mathrm{~kg}-$ van den Brink 1955), differ in weight by a factor of 4 to 8 . The weight of a mountain hare is approximately $1 / 4$ the weight of a medium sized lynx. By comparison, a roe deer or a juvenile reindeer weighs 1-4 times as much as the predator. The two categories, representing a combined total of $93 \%$ of the largest prey items measured by frequency, may thus be considered two very distinct categories of prey. The homogeneity in the overall ratio of cervids and small game in the diet of self-provisioning lynx between regions and sampling periods was tested by general log-linear models (Model selection procedure - Norusis 1994). The variables entered were prey type "PR" (cervid or small game), region "RE" [1: southern Norway (all counties south of Sør-Trøndelag county), 2: central Norway (The counties of Sør-Trndelag and Nord-Trøndelag) and 3: northern Norway (all counties north of Nord-Trøndelag county)], and sampling period PE (1960-1966 vs 1988-1996). Since the sex-ratio may differ somewhat between the regions (Kvam 1990), the analyses were conducted separately for each sex. Log-linear models have the advantage that the significance of the interaction terms between three or more factors (here PR, RE and PE) can be computed.

Since virtually only two prey categories were exploited, logistic regression was used with prey category as the dependent variable in the analysis of prey choice. Independent variables were entered by forward selection procedure (Norusis 1994). The following factors were entered: (1) sex, (2) body weight, (3) general condition index, (4) age, and (5) season. Because the factors of sex and body weight were highly correlated, the analysis was furthermore repeated on each sex separately to resolve any additional effects of body weight not measured in the combined analysis.

The difference between two means was tested by Student's $t$-test. Chi-square statistics were used for tests of association. In $2 \times 2$ cross-tables we used Yate's continuity correction. The level of significance was $<0.05$. All tests were two-tailed.

\section{Results}

\section{Weight and condition}

Both male and female lynx can be considered as fully grown from the age of 2 years. From that age, no significant increase in body weight with age occurs (Animals $\geq 2$ years. Males: $r_{\mathrm{s}}=0.135, p=0.11, n=142$; females: $r_{\mathrm{s}}=0.129, p=$ $0.16, n=121$ ).

Males are approximately $24 \%$ heavier than females in both seasons (Table 1), and subadults are approximately $10 \%$ lighter than adults of the same sex (Table 1). The resulting body weight distributions of the two sexes overlap extensively (Fig. 1), with approximately $32 \%$ of the body weight variation $\left(R^{2}=0.324\right.$, $p<0.0001, n=240$ ) of independent lynx in the diet analysis ( $\geq 1 \mathrm{yr}$ ) being explained by sex.

\section{Diet}

Eighty-one percent of the stomachs of independent ( $\geq 1 \mathrm{yr}$ ) lynx, and $75 \%$ of the stomachs of juveniles contained prey remains. The cervids were roe deer (137), reindeer (124), elk Alces alces (3) and red deer Cervus elaphus (1), and 32 were unidentified cervids. Small game were mountain hares (87) and tetraonids and other birds (24) (Table 2). In addition, in 13 cases the largest items were carnivores 
Table 1. Mean body weight (Wt; in $\mathrm{kg}$ ) of lynx according to unskinned carcasses, with corresponding standart deviation (SD) and sample size $(n)$. Sexual dimorphism index in percent: DI $=1-$ (male $\mathrm{Wt} /$ female $\mathrm{Wt}) \times 100 \%$, winter: November-April, summer: May-October, juveniles: $<1 \mathrm{yr}$, subadults: 1-2 yr, Adults: $\geq 2$ yr.

\begin{tabular}{|c|c|c|c|c|c|c|c|}
\hline & \multicolumn{3}{|c|}{ Males } & \multicolumn{3}{|c|}{ Females } & \multirow{2}{*}{$\begin{array}{l}\text { DI } \\
\%\end{array}$} \\
\hline & Wt & SD & $n$ & Wt & $\mathrm{SD}$ & $n$ & \\
\hline \multicolumn{8}{|l|}{ Winter } \\
\hline Juveniles & 9.5 & 2.9 & 82 & 9.7 & 2.7 & 69 & -2 \\
\hline Subadults & 17.9 & 2.6 & 71 & 15.4 & 2.4 & 47 & 16 \\
\hline Adults & 20.2 & 2.7 & 144 & 16.2 & 2.5 & 118 & 25 \\
\hline \multicolumn{8}{|l|}{ Summer } \\
\hline Subadults & 16.9 & 2.3 & 14 & 13.6 & 2.4 & 8 & 24 \\
\hline Adults & 18.3 & 2.6 & 22 & 14.8 & 2.0 & 17 & 24 \\
\hline
\end{tabular}

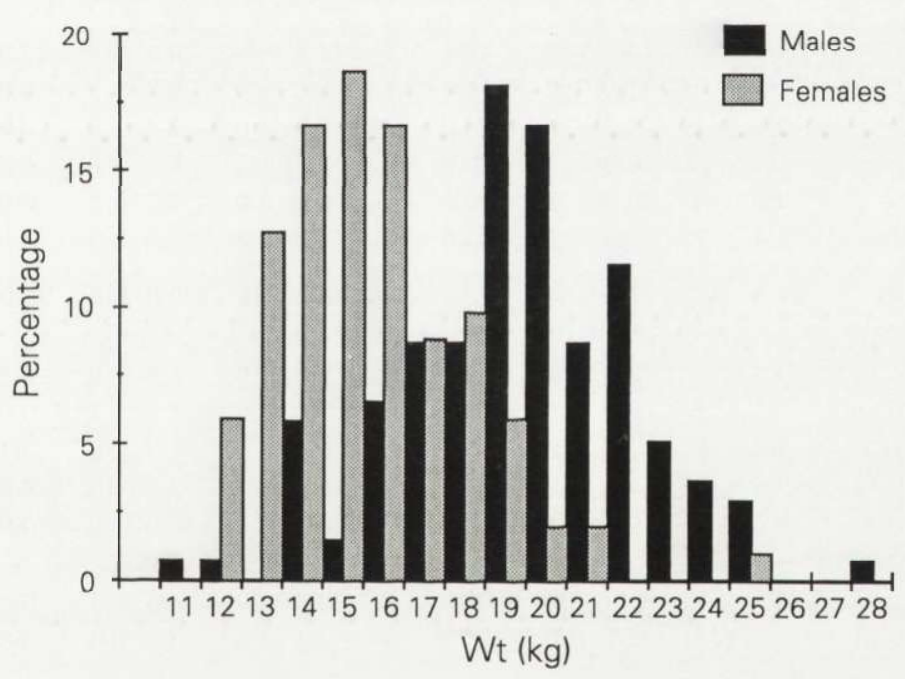

Fig. 1. Percentage distribution by sex of body weights of independent lynx $(\geq 1 \mathrm{yr})$ in the logistic regression model. Males: $n=138$, females: $n=102$.

and in 8 cases rodents. Overall, cervids and small game constituted $93 \%$ of the largest food item observed.

A test of homogeneity within each prey category revealed no indication of any association with sex, age group or body weight: males and females from Central Norway foraged equally on reindeer and roe deer $\left(\chi^{2}=0.00, p=1.00, n=54\right)$, and males and females all over the country foraged equally on birds and mountain hares $\left(\chi^{2}=0.18, p=0.67, n=76\right)$. Neither were there any differences in the cervid-small game ratio between the early and the late sampling period (males: 
Table 2. Food item occurrence. Of statistical reasons is only one prey selected in cases where more than one prey is registered for a lynx: the largest prey item in stomachs, the first found prey in intestines or the last killed prey in hunters's reports. Only cervids and small game are considered in the quantitative analyses (see text for explanation).

\begin{tabular}{|c|c|c|c|c|c|c|c|c|c|c|c|c|c|c|}
\hline \multirow{3}{*}{ Prey species } & \multicolumn{8}{|c|}{ Data source } & \multicolumn{6}{|c|}{ Age group } \\
\hline & \multicolumn{2}{|c|}{$\begin{array}{c}\text { Stomachs } \\
1960-66\end{array}$} & \multicolumn{2}{|c|}{$\begin{array}{l}\text { Stomachs } \\
1988-96\end{array}$} & \multicolumn{2}{|c|}{$\begin{array}{c}\text { Intestines } \\
1990-95\end{array}$} & \multicolumn{2}{|c|}{$\begin{array}{l}\text { Hunter's } \\
\text { reports }\end{array}$} & \multicolumn{2}{|c|}{ Total } & \multicolumn{2}{|c|}{$<1 \mathrm{yr}$} & \multicolumn{2}{|c|}{$\geq 1 \mathrm{yr}$} \\
\hline & $\%$ & $n$ & $\%$ & $n$ & $\%$ & $n$ & $\%$ & $n$ & $\%$ & $n$ & $\%$ & $n$ & $\%$ & $n$ \\
\hline Capreolus capreolus & 22.3 & 35 & 39.3 & 77 & 11.1 & 1 & 30.4 & 24 & 31.1 & 137 & 31.1 & 41 & 32.8 & 96 \\
\hline Rangifer tarandus & 36.9 & 58 & 18.9 & 37 & 11.1 & 1 & 35.4 & 28 & 28.1 & 124 & 26.0 & 34 & 27.6 & 81 \\
\hline Alces alces & 1.3 & 2 & 0.5 & 1 & 0.0 & 0 & 0.0 & 0 & 0.6 & 3 & 0.0 & 0 & 1.2 & 3 \\
\hline Cervus elaphus & 0.6 & 1 & 0.0 & 0 & 0.0 & 0 & 0.0 & 0 & 0.2 & 1 & 0.0 & 0 & 0.3 & 1 \\
\hline Unidentified cervids & 3.2 & 5 & 10.7 & 21 & 55.6 & 5 & 1.3 & 1 & 7.5 & 32 & 4.6 & 6 & 7.8 & 23 \\
\hline Cervids total: & 64.3 & 101 & 69.4 & 136 & 77.8 & 7 & 67.1 & 53 & 67.3 & 297 & 61.8 & 81 & 69.6 & 204 \\
\hline Lepus timidus & 21.0 & 33 & 23.0 & 45 & 11.1 & 1 & 11.4 & 9 & 20.0 & 88 & 22.9 & 30 & 19.8 & 58 \\
\hline Tetrao urogallus & 0.0 & 0 & 1.0 & 2 & 11.1 & 1 & 0.0 & 0 & 0.7 & 3 & 0.8 & 1 & 0.7 & 2 \\
\hline Tetrao tetrix & 0.6 & 1 & 2.0 & 4 & 0.0 & 0 & 0.0 & 0 & 1.1 & 5 & 0.0 & 0 & 1.2 & 3 \\
\hline Lagopus lagopus & 1.3 & 2 & 0.5 & 1 & 0.0 & 0 & 3.8 & 3 & 1.4 & 6 & 0.8 & 1 & 1.7 & 5 \\
\hline Bonasa bonasia & 0.0 & 0 & 0.5 & 1 & 0.0 & 0 & 0.0 & 0 & 0.2 & 1 & 0.0 & 0 & 0.3 & 1 \\
\hline Unidentified birds & 4.4 & 7 & 0.5 & 1 & 0.0 & 0 & 1.3 & 1 & 2.0 & 9 & 1.5 & 2 & 0.2 & 7 \\
\hline Small game total: & 27.4 & 43 & 27.6 & 54 & 22.2 & 2 & 16.5 & 13 & 27.9 & 110 & 26.0 & 34 & 25.9 & 76 \\
\hline Vulpes vulpes & 0.0 & 0 & 0.0 & 0 & 0.0 & 0 & 7.6 & 6 & 1.4 & 6 & 2.3 & 3 & 1.2 & 3 \\
\hline Unidentified carnivores & 4.4 & 7 & 0.0 & 0 & 0.0 & 0 & 0.0 & 0 & 1.6 & 7 & 0.0 & 0 & 1.7 & 5 \\
\hline Rodents & 3.2 & 5 & 1.5 & 3 & 0.0 & 0 & 0.0 & 0 & 1.8 & 8 & 3.1 & 4 & 0.7 & 5 \\
\hline Waste/carrion & 0.6 & 1 & 1.0 & 2 & 0.0 & 0 & 8.9 & 7 & 2.3 & 10 & 6.8 & 9 & 0.3 & 1 \\
\hline Cat/dog & 0.6 & 1 & 0.5 & 1 & 0.0 & 0 & 0.0 & 0 & 0.5 & 2 & 0.0 & 0 & 1.7 & 5 \\
\hline Observations & 100 & 157 & 100 & 196 & 100 & 9 & 100 & 79 & 100 & 441 & 100 & 131 & 100 & 293 \\
\hline $\begin{array}{l}\text { Observations within } \\
\text { the analyses }\end{array}$ & 91 & 143 & 97 & 190 & 100 & 9 & 84 & 66 & 93 & 408 & 88 & 115 & 96 & 280 \\
\hline
\end{tabular}

$p=0.570$, females: $p=0.121$ ), between the three regions (males: $p=0.393$, females: $p=0.686$ ), or any higher-order interaction of these factors (males: $p=0.755$, females: $p=0.637$ ) in the log-linear model.

As expected, the diet of juveniles did not differ from the diet of adult females $\left(\chi^{2}=0.611, p=0.43, n=183\right)$ (Fig. 2). All subgroups of lynx, irrespective of status, foraged more often on cervids than on small game (Fig. 2). Males generally preferred cervids more than females $\operatorname{did}\left(\chi^{2}=14.13, p=0.0002, n=280\right)$, but the difference was slight $\left(R^{2}=0.054\right)$. The food niche overlap between the sexes, calculated by Pianka's (1973) index, was 0.94 . 


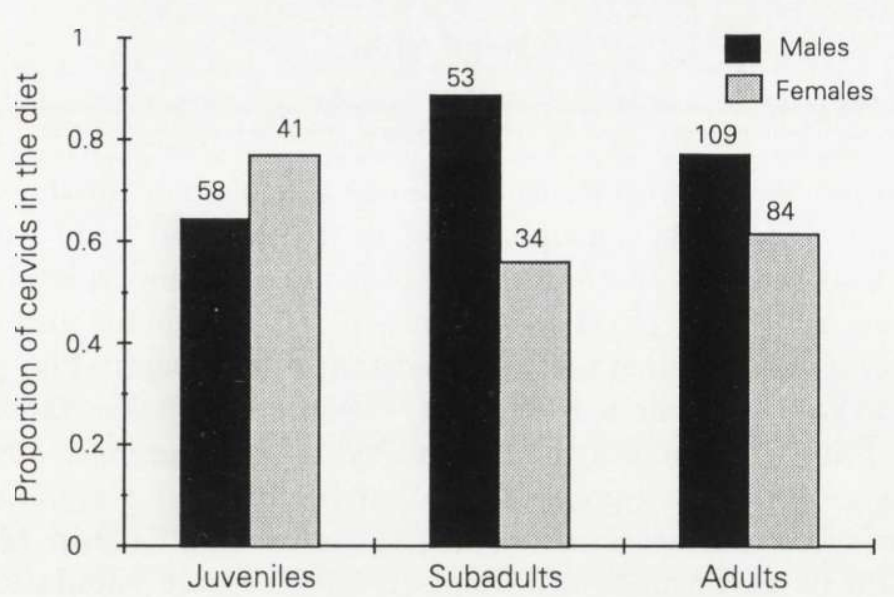

Fig. 2. Proportions of cervids in the diet of the various age calsses. Juveniles: $<1$ yr, subadults: $1-2$ yr, adults: $\geq 2 \mathrm{yr}$. The number of observations for each group are shown above the bars.

In a logistic regression model, $3.9 \%$ of the variation in prey preference could be explained by sex (Table 3). When all the factors were included in the model, sex was the only significant one for prey preference. An apparent significant effect of body weight disappeared after sex had been entered (Table 3 ). When the analysis was repeated for each sex separately, body weight tended to have an additive effect amongst females, but clearly not among males (Table 3 ).

Univariate tests of the five factors between food groups revealed very much the same result as the logistic regression model before the factors were applied together: age and season did not seem to have any influence on prey choice $(p>0.9)$, nor did the general condition index $(p>0.10)$.

Table 3. Effect of various factors on prey choice, fed into logistic regression models. The value of $R^{2}$ denotes approximately how much the variation in diet choice is explained by the independent variable.

\begin{tabular}{|c|c|c|c|c|c|c|c|c|}
\hline \multirow{3}{*}{ Factor } & \multirow{2}{*}{\multicolumn{2}{|c|}{$\begin{array}{c}\begin{array}{l}\text { Univariate effect of } \\
\text { each separate factor }\end{array} \\
\text { All } \\
(n=240)\end{array}$}} & \multicolumn{6}{|c|}{ Weighted effect of each factor when fed stepwise } \\
\hline & & & \multicolumn{2}{|c|}{$\begin{array}{c}\text { All } \\
(n=240)\end{array}$} & \multicolumn{2}{|c|}{$\begin{array}{c}\text { Males } \\
(n=138)\end{array}$} & \multicolumn{2}{|c|}{$\begin{array}{l}\text { Females } \\
(n=102)\end{array}$} \\
\hline & $R^{2}$ & $p$ & $R^{2}$ & $p$ & $R^{2}$ & $p$ & $R^{2}$ & $p$ \\
\hline Sex & 0.039 & 0.0002 & 0.038 & 0.0003 & & & & \\
\hline Body weight & 0.030 & 0.0010 & 0.000 & 0.122 & 0.000 & 0.705 & 0.012 & 0.054 \\
\hline Condition index & 0.000 & 0.209 & 0.000 & 0.386 & 0.000 & 0.924 & 0.000 & 0.797 \\
\hline
\end{tabular}




\section{Discussion}

\section{Methods}

In a statistical sense, prey choice is clearly independent of the variables sex, age and season. A possible dependency of food choice on body weight and the general condition index is more obscure; because of phenotypic plasticity these two factors may reflect an effect as much as a cause (Holmes and Powell 1994). Pulliainen et al. (1995) for instance, showed that a lynx population preying solely on small game had a lower average body weight and lower fat deposits than another population with access to white-tailed deer Odocoileus virginianus. We would therefore stress that a possible relationship between weight and condition, and prey choice, does not necessarily reflect a causal relationship. Ideally, studies like this should be performed on animals from the same population, facing the same environmental conditions. The present material has been collected over a span of $1000 \mathrm{~km}$, but the fundamental food niche, measured as the big game/small game ratio in the diet, is the same all over the country. However, since no signs of regional differences in food habit, body weight or general condition have been found, we believe that this material represents animals experiencing similar environmental conditions.

\section{Age and experience}

If the two types of prey differed in catchability, we would have expected subadults to handle the most troublesome type less efficiently, which in turn would result in a lower diet frequency. The reason for the total absence of age influence on prey choice may thus either be that both types are equally difficult to catch for an inexperienced hunter, or that subadults are already experienced hunters in late winter after almost a year on their own.

\section{The significance of sex or weight for diet choice}

There are few sex-specific investigations of solitary carnivores, but in a number of species of mustelids the larger males have been found to forage on larger prey than females (Erlinge 1979, Moors 1980, Birks and Dunstone 1985, Heggberget and Moseid 1994). All previous studies where cervids have been part of the lynx or bobcat diet (Fritts and Sealander 1978, Litvaitis et al. 1984, 1986, Matlack and Evans 1992, Pulliainen et al. 1995), have also shown a complete or partial prey size segregation towards males killing a larger proportion of cervids than females. The findings of sexually determined prey size segregation in the diets of carnivores have in general been explained by morphologically constrained differences in optimal prey size: either because of the larger size of the males, which makes them more capable of killing larger prey than females (Fritts and Sealander 1978, Litvaitis et al. 1984, 1986, Birks and Dunstone 1985, Matlack and Evans 1992, Pulliainen et al. 1995), or as seen among weasels, where the females are able to hunt prey inaccessible to males (Erlinge 1979, see also the review by King 1989). 
However, since all the studies have tested differences in prey choice univariately, a general conclusion about the significance of size for the differentiated prey choice of males and females cannot be drawn.

Two adaptive models have been proposed to explain the evolution of sexual dimorphism of solitary carnivores. One explanation is that sexual size dimorphism in solitary carnivores is maintained by directional selection on different optimal prey size between males and females: the more sexual dimorphism, the less inter-sexual competition (Dayan et al. 1989, 1990, Dayan and Simberloff 1994). Alternatively, sexual dimorphism of carnivorous mammals is explained to be a result of sexual selection on males favouring large individuals in mating situations, whereas females are optimised for raising their offspring by, for instance, being efficient foragers (Erlinge 1979, Moors 1980, Pulliainen 1981, Holmes and Powell 1994).

Since the first "prey segregation" hypothesis explains the evolution of sexual dimorphism by natural selection on optimal prey size, it predicts predator size to be closely correlated with mean prey size. In contrast, the second sexual selection hypothesis rather interprets sexually determined differences in prey size to be a secondary result of morphological constraints independently of intraspecific competition; hence the intraspecific correlation between predator size and prey size should be less stringent or even absent.

The "niche segregation" hypothesis is supported by the findings that predator size is highly correlated with mean prey size in a number of studies at the interspecific level (eg Rosenzweig 1966, Kruuk 1982, Karanth and Sunquist 1995), but also within species, eg between different populations of mountain lions Felis concolor (Iriarte et al. 1990) and stoats Mustela erminea (Erlinge 1987). At the population level, Litvaitis et al. (1984, 1986) claimed a positive relationship between the proportion of deer in the diet and body size of bobcats, independent of sex or age, but nevertheless tested by univariate methods.

The sexual selection hypothesis is supported by data showing that males of solitary carnivores roam disproportionately larger areas than females do, in relation to their body size, a behaviour that cannot be explained by optimal foraging theory alone (Sandell 1989). The fact that the sexes of solitary carnivores express differentiated behaviour, as eg seen in the area use, may result in different encounter rates with prey due to different movement patterns and/or habitat use.

In our material, sex was the only factor that clearly affected prey choice; males killed slightly more cervids than females. If there were an independent effect of size, we would expect it to have resulted in an increase in the size factor in the logistic model; no such effect appeared. The (nonsignificant) tendency towards a body weight effect on female food choice may, however, indicate that the smallest individuals of the smallest sex may have problems handling the largest prey types. Males, on the other hand, show no signs of any additive effect of body weight. If a difference in weight were the principal determinant for hunting success, we would also expect subadults, which on average are $2 \mathrm{~kg}$ lighter than adults, to 
kill even fewer cervids than fully grown adults. This is clearly not indicated in our material (Fig. 2). We must therefore conclude that prey choice in lynx in general does not seem to be influenced by the body weight of the predator.

Studies by Jędrzejewski et al. (1993) and Okarma et al. (1995) have shown that lynx do not select roe deer of a certain size or age class, but they do select calves and females when preying upon larger cervids such as reindeer (Haglund 1966) and red deer (Okarma 1984, Jędrzejewski et al. 1993). Jędrzejewski et al. (1993) and Okarma et al. (1995) found that in areas where roe deer coexist with larger cervids, roe deer are clearly preferred. If the preference of males for cervids is caused by a greater efficiency at killing large species, we would also expect males to kill proportionately more large ungulate species than females do. In Norway, this should result in a higher proportion of reindeer (winter weight: $50-90 \mathrm{~kg}$ ) than of roe deer (winter weight: $16-30 \mathrm{~kg}$ ) in the male diet compared with the female diet. Again, our data do not confirm this. Moreover, it is our experience that the European lynx is physically powerful enough to kill even very large prey. We even have evidence of a starved (radio-collared) juvenile weighing less than $12 \mathrm{~kg}$, regularly killing fully grown reindeer, the largest weighing approximately $65 \mathrm{~kg}$ (P. Sunde and T. Kvam, unpubl.). Thus, small individuals in a lynx population may kill even fully grown individuals of medium-sized cervid species. Haglund (1966) found the attack success in winter to be negatively correlated with prey size. Any possible weight-related skill at hunting larger-size prey may thus just as well reflect the poorer hunting success of the heavier, clumsier males with small game, as a male superiority at killing cervids.

We believe that the most likely explanation for the sexual prey size segregation is that male lynx kill proportionately more cervids due to differences in habitat choice and/or area utilisation. Males of the European lynx range areas of 1-3 times the size of female home ranges (Breitenmoser et al. 1993, P. Sunde et al., in prep.). When males roam much larger areas and have far longer daily roaming distances than females, this may indicate differences in habitat use and hunting pattern. Locating small game and ungulates may require different behavioural tactics. While walking with juveniles, females may spend more time locally searching for hares, for instance, whereas males may encounter prey along their routes or search out potential prey habitats in their vicinity. A large prey is likely to be easier to detect at a distance than a small one.

\section{Conclusions}

On the basis of the information presently available, we do not find sufficient evidence to conclude that body size in itself is the decisive cause of the difference in diet between the sexes. We rather propose that sexually determined differences in prey choice are an effect of differentiated behaviour. Hence, the data also suggest 
that sexual dimorphism in the Eurasian lynx is not a result of natural selection towards avoidance of intraspecific competition.

However, the results should be corroborated through studies of living animals. By snowtracking individuals identified by telemetry it would be possible to provide evidence about which factor determines prey selection and hunting success. We suggest that the difference in prey preference between sexes can be interpreted in terms of the following hypotheses:

I. The different predation patterns reflect sexual differences in habitat choice and area utilisation, which in turn result in different encounter rates with different types of prey.

II. Differences in prey size in lynx populations are caused by morphological constraints due to differences in body size.

If the segregation can be explained by hypothesis I, the encounter rates of the two types of prey are expected to differ between sexes, and perhaps also between age groups. If it can be explained by hypothesis II, males are expected to have a higher rate of success on encounters with cervids than females, especially on ungulate types that are generally avoided, and females and subadults will have a higher rate of success on encounters with small game.

No studies have so far compared possible sex-related differences on local movements and habitat use patterns by tracking identified, radio-collared individuals over snow. Nor has anybody tested the success rates of attacks by each sex on prey of different sizes. Such studies would also reveal the importance of the experience of juveniles vs subadults and adults, and the effect on the survival rate of juveniles after being abandoned by their mother in late winter. We further recommend future food habit studies to separate the possible effects of implicating variables, mainly sex and size.

Acknowledgements: We are grateful to T. Secher-Jensen, G. Nachman, K. Overskaug and three anonymous referees for valuable comments on this manuscript. R. Binns and J. R. Sciabà improved the language.

\section{References}

Bekoff M. and Daniels T. J. 1984. Life history patterns and the comparative social ecology of carnivores. Annual Review of Ecology and Systematics 15: 191-232.

Birkeland K. H. and Myrberget S. 1980. The diet of the lynx Lynx lynx in Norway. Fauna norvegica Serie A 1: 24-28.

Birks J. D. and Dunstone N. 1985. Sex-related differences in the diet of the mink Mustela vision. Holarctic Ecology 8: 245-252.

Breitenmoser U. and Haller H. 1993. Patterns of predation by reintroduced European lynx in the Swiss Alps. Journal of Wildlife Management 57: 135-144.

Breitenmoser U., Kaczensky P., Dötterer M., Breitenmoser-Würsten C., Capt S., Bernhart F. and Liberek M. 1993. Spatial organization and recruitment of lynx (Lynx lynx) in a re-introduced population in the Swiss Jura Mountains. Journal of Zoology, London 231: 449-464.

Dayan T. and Simberloff D. 1994. Character displacement, sexual dimorphism, and morphological variation among British and Irish mustelids. Ecology 75: 1063-1073. 
Dayan T., Simberloff D., Tchernov E. and Yom-Tom Y. 1989. Inter- and intraspecific character displacement in mustelids. Ecology 70: 1526-1539.

Dayan T., Simberloff D., Tchernov E. and Yom-Tom Y. 1990. Feline canines: community-wide character displacement among the small cats of Israel. American Naturalist 136: 39-60.

Eisenberg J. F. 1982. Life history strategies of the Felidae: variations on a common theme. [In: Cats of the World: Biology, conservation, and management. S. D. Miller and D. D. Everett, eds]. Proceedings of the 2nd International Symposium 1982. The National Wildlife Federation, Institute for Wildlife Research. Washington, D.C.: 293-303.

Erlinge S. 1979. Adaptive significance of sexual dimorphism in weasels. Oikos 33: 233-245.

Erlinge S. 1981. Food preference, optimal diet and reproductive output in stoats Mustela erminea in Sweden. Oikos 36: 303-315.

Erlinge S. 1987. Why do European stoats Mustela erminea not follow Bergmann's rule? Holarctic Ecology 10: 33-39.

Fritts S. and Sealander J. A. 1978. Diets of bobcats in Arkansas with special reference to age and sex differences. Journal of Wildlife Management 42: 533-539.

Grue M. and Jensen B. 1979. Review of the formation of incremental lines in tooth cementum of terrestrial animals. Danish Review of Game Biology 11: 1-48.

Haglund B. 1966. Winter habits of the Lynx (Lynx lynx L.) and Wolverine (Gulo gulo L.) as revealed by tracking in the snow. Viltrevy 4: 81-299.

Heggberget T. M. and Moseid K-E. 1994. Prey selection in coastal Eurasian otters Lutra lutra. Ecography 17: 331-338.

Holmes T. and Powell R. A. 1994. Morphology, ecology, and the evolution of sexual dimorphism in the North American Martes. [In: Martens, sables, and fishers. Biology and conservation. S. W. Buskirk, A. S. Harestad, M. G. Raphael and R. A. Powell, eds]. Cornell University press, New York: $72-84$.

Iriarte J. A., Franklin W. L., Johnson W. E. and Redford K. H. 1990. Biogeographic variation of food habits and body size of the American puma. Oecologia 85: 185-190.

Jędrzejewski W., Schmidt K., Miłkowski L., Jędrzejewska B. and Okarma H. 1993. Foraging by lynx and its role in ungulate mortality: the local (Białowieża Forest) and the Palaearctic viewpoints. Acta Theriologica 38: 385-403.

Karanth K. U. and Sunquist M. E. 1995. Prey selection by tiger, leopard and dhole in tropical forests. Journal of Animal Ecology 64: 439-450.

King C. M. 1989. The advantages and disadvantages of small size to weasels, Mustela species. [In: Carnivore behaviour, ecology, and evolution. J. L. Gittleman, ed]. Chapman and Hall, London: 302-334.

Kruuk H. 1982. Interactions between Felidae and their prey species: a review. [In: Cats of the World: Biology, conservation, and management. S. D. Miller and D. D. Everett, eds]. Proceedings of the 2nd International Symposium 1982. The National Wildlife Federation, Institute for Wildlife Research. Washington, D.C.: 353-374.

Kvam T. 1984. Age determination in the European lynx (Lynx lynx) by incremental lines in tooth cementum. Acta Zoologica Fennica 171: 221-223.

Kvam T. 1990. Population biology of the European lynx (Lynx lynx) in Norway. Ph D thesis, University of Trondheim, Trondheim: 1-34.

Kvam T. 1991. Reproduction in the European lynx (Lynx lynx). Zeitschrift für Säugertierkunde 56: $146-158$.

Litvaitis J. A., Stevens C. J. and Mautz W. W. 1984. Age, sex, and weight of bobcats in relation to winter diet. Journal of Wildlife Management 48: 632-635.

Litvaitis J. A., Clark A. G. and Hunt J. L. 1986. Prey selection and fat deposits of bobcats Felis rufus during autumn and winter in Maine. Journal of Mammalogy 67: 389-392.

Maehr D. S. and Brady J. R. 1986. Food habits of bobcats in Florida. Journal of Mammalogy 67: 133-138. 
Matlack C. R. and Evans A. J. 1992. Diet and condition of bobcats, Lynx rufus, in Nova Scotia during autumn and winter. Canadian Journal of Zoology 70: 1114-1119.

Moors P. J. 1980. Sexual dimorphism in the body size of mustelids (Carnivora): the role of food habits and breeding systems. Oikos 34: 147-158.

Norusis M. J. 1994. SPSS Advanced statistics ${ }^{\text {TM }}$ 6.1. SPSS Inc., Chicago IL: 1-606.

Okarma H. 1984. The physical condition of red deer falling as prey to the wolf and lynx and harvested in the Carpathian Mountains. Acta Theriologica 29: 283-290.

Okarma H., Jędrzejewska B., Jędrzejewski W., Krasiński A. and Miłkowski L. 1995. The roles of predation, snow cover, acorn crop, and man-related factors on ungulate mortality in Białowieża Forest, Poland. Acta Theriologica 40: 197-217.

Palomares F., Ferreras P., Fedriani J. M. and Delibes M. 1996. Spatial relationships between Iberian lynx and other carnivores in an area of south-western Spain. Journal of Applied Ecology 33: 5-13.

Pianka E. R. 1973. The structure of lizard communities. Annual Review of Ecology and Systematics 4: 53-74.

Pulliainen E. 1981. Winter diet of Felis lynx L. in SE Finland as compared with the nutrition of other northern lynxes. Zeitschrift für Säugertierkunde 46: 246-259.

Pulliainen E., Lindgren E. and Tunkkari P. S. 1995. Influence of food availability and reproductive status on the diet and body condition of the European lynx in Finland. Acta Theriologica 40: 181-196.

Rosenzweig M. L. 1966. Community structure in sympatric Carnivora. Journal of Mammalogy 47: $602-612$.

Sandell M. 1989. The mating tactics and spacing patterns of solitary carnivores. [In: Carnivore behaviour, ecology, and evolution. J. L Gittleman, ed]. Chapman and Hall, London: 164-182

van den Brink E. 1955. [The mammals of Europe], (Norwegian edition by Pedersen J. A. 1968). Tiden Norsk Forlag, Oslo: 1-220. [In Norwegian]

Received 16 August 1996, accepted 16 March 1997. 